\title{
PELATIHAN LITERASI \\ BAHASA INDONESIA TERINTEGRASI BAHASA IBU BAGI GURU KELAS AWAL
}

\author{
Kristoforus Dowa Bili'), Yohana Claudia Dhian Ariani Harbelubun'), Imakulata Magi Loda ${ }^{3}$ ) \\ ${ }^{1}$ PGSD, STKIP Weetebula \\ ${ }^{2} \mathrm{FBS}$, Universitas Atma Jaya Jakarta \\ ${ }^{3}$ PGSD, STKIP Weetebula \\ Email: ${ }^{1}$ itto_stkipwet@yahoo.com,_2dhian.ariani@gmail.com, ${ }^{3}$ imakulata.loda@gmail.com
}

\begin{abstract}
Abstrak
Pelatihan literasi bahasa Indonesia terintegrasi bahasa ibu bagi guru kelas awal Sekolah Dasar (SD) di Kecamatan Wewewa Barat, Kabupaten Sumba Barat Daya, NTT dilatarbelakangi adanya hasil kajian Pengembangan Kapasitas dan Analisis Pendidikan (ACDP) yang menemukan masalah bahwa anak-anak di Sumba cenderung memakai bahasa ibu. Selain itu, ditemukan 53\% guru di Sumba hanya lulusan Sekolah Menengah Atas (SMA) dan 10 dari 12 guru Kelas 2 tidak mendapatkan pelatihan pengajaran membaca. Realita ini diperpuruk dengan $42 \%$ kepala sekolah, hanya lulusan SMA. Hasil kajian ini menyebabkan gap antara siswa yang cenderung menggunakan bahasa ibu dengan tingkat pendidikan guru lulusan SMA. Dampak gap tersebut yakni pengajaran baca-tulis oleh guru menjadi kurang efektif. Oleh karena itu, guru kelas awal membutuhkan pelatihan pembelajaran literasi terintegrasi bahasa ibu. Hal ini dipandang sebagai solusi urgen persoalan tersebut. Hasil kegiatan pengabdian ini adalah guru memahami pentingnya pembelajaran bahasa Indonesia dengan mengintegrasikan bahasa ibu pada kelas awal SD, memahami dan terampil menerapkan metode Membaca dan Menulis Permulaan (MMP) terintegrasi bahasa ibu dalam pembelajaran kelas awal, memiliki keterampilan menyusun media (kartu huruf, suku kata, dan kata) bahasa Indonesia mengintegrasikan bahasa ibu, dan memiliki pemahaman-keterampilan menggunakan penilaian MMP dengan menggunakan format dan rubrik penilaian.
\end{abstract}

Kata Kunci: Pelatihan, Literasi, Bahasa Indonesia, Bahasa Ibu.

\begin{abstract}
Indonesian literacy training integrated with mother tongue for early years primary school teachers in Wewewa Barat District, Southwest Sumba Regency, NTT was motivated by the study of ACDPI (2015). The study found that children in Sumba normally use mother tongue in their daily basis. It also found that 53\% of teachers in Sumba merely graduated from senior high school (SMA) and 10 out of 12 teachers of Year 2 did not receive how-to-teach-reading training. $42 \%$ of principals who are SMA graduates aggravated the fact. This study result shows the gap between students who use mother tongue and teacher's low qualification. Its impact is a less-effective reading-writing teaching. Integrated literacy learning training, therefore, is a must; this is seen as an urgent solution. The result of this community service: the teachers understand the importance of learning literacy integrated with mother tongue, understand and are skilled in applying the Preliminary Reading and Writing method (MMP) integrated with mother tongue, possess the skills of creating Indonesian learning media (letter cards, syllables, and words) integrated with mother tongue, and have comprehension and skill in using MMP assessment by employing the format and assessment rubric.
\end{abstract}

Keywords: Training, Literacy, Indonesian, Mother Tongue. 


\section{PENDAHULUAN}

Kemitraan untuk Pengembangan Kapasitas dan Analisis Pendidikan (ACDP) merilis sejumlah permasalahan pendidikan yang mendesak untuk segera dituntaskan di Sumba, Nusa Tenggara Timur. Permasalahan pendidikan yang ditemukan ACDP adalah: 1 . proporsi guru yang tidak berlatar belakang pendidikankeguruan, 2. ketersediaan dan distribusi guru, 3. alokasi sumber daya yang berkelanjutan bagi sekolah swasta, 4 . kualitas mengajar, 5. kesiapan anak belajar. Sejumlah permasalahan di Sumba membuat anak-anak tidak mampu membaca dan angka mengulang di kelas II cukup tinggi (ACDP, 2015: 1-10).

Permasalahan membaca pada anak sekolah dasar di daerah terpencil cukup menjadi perhatian serius. Sebuah studi menemukan bahwa dari tiga anak, hanya satu yang mampu membaca bahasa Indonesia. Awalnya kemampuan literasi ini diakibatkan karena kemampuan guru yang mengajar, hanya sebatas lulusan SMA. Kemampuan guru yang hanya sebatas Sekolah Menengah Atas (SMA) sebanyak 53 persen dan diperburuk dengan ditemukannya juga jenjang pendidikan kepala sekolah yang hanya lulusan SMA. Sebanyak 42 persen kepala sekolah di Sumba adalah lulusan SMA (ACDP, 2015: 42-47). Kualitas guru dan kepala sekolah yang hanya lulusan SMA ini, membuat cara mengajarkan baca dan tulis menjadi kurang efektif. Kelompok Kerja Guru atau KKG, yang dimaksudkan agar para guru aktif mencari terobosan dalam menangani masalah literasi juga tidak berjalan dan tidak mampu meningkatkan kualitas mereka.

Selain itu, anak-anak di Sumba juga cenderung masih memakai bahasa ibu yang membuat kemampuan guru untuk mengajar, harus ditingkatkan. Lima puluh persen anakanak di Sumba masih menggunakan bahasa ibu. Contohnya, saat guru bertanya menggunakan bahasa Indonesia, hanya 41 persen siswa yang mampu menjawab dengan bahasa Indonesia (ACDP, 2015: 65). Ketika anak masuk sekolah, bahasa yang harus digunakan adalah bahasa Indonesia yang baik dan benar, padahal bahasa yang mereka kuasai adalah bahasa ibu dan guru menggunakan bahasa Indonesia. Bahkan, guru-guru pendatang tidak mampu berbahasa daerah sehingga timbullah persoalan. Anak tidak memahami apa yang disampaikan guru dan guru tidak memahami bagaimana cara menjelaskan pada anak dalam bahasa daerah. Siswa stres guru pun stress. Persoalan kebahasaan seperti inilah yang mungkin turut andil mengakibatkan guru meninggalkan tugas dan kewajibannya. Jika hal ini terusmenerus dipaksakan tidak akan menghasilkan prestasi belajar yang memuaskan. Hal yang terjadi justru sebaliknya prestasi belajar siswa semakin lama akan semakin menurun. Hal ini karena murid tidak memiliki pondasi yang kuat pada struktur dan kosa kata bahasa Indonesia.

Atas dasar hal ini diadakan berbagai percobaan pembelajaran multi bahasa di banyak negara, termasuk Filipina. Pada 2012, Pemerintah Filipina memperkenalkan penggunaan bahasa Ibu sebagai bahasa pengantar di sekolah-sekolah dasar pada kelas awal. Pemerintah melakukan percobaan sekolah yang diajarkan dengan bahasa Ibu secara total pada 3 kelas awal sambil diberikan bahasa Inggris dan Filipina secara lisan, kemudian terdapat sekolah yang diajarkan dengan bahasa Inggris dan Filipina. Hasilnya sangat positif. Kesimpulan menunjukkan bahwa, setelah siswandigabungkan pada kelas 4 dan selanjutnya, siswa yang diajarkan dengan bahasa Ibu menunjukkan rata-rata lebih unggul $75 \%$ pada tes standar pengetahuan dan keterampilan matematika,sedangan siswa di sekolah pembanding hanya memperoleh rata-rata $50 \%$. Perbedaan serupa ditemukan pada hasil tes membaca, Bahasa Inggris dan Filipina, (ACDP, 2014). Pada sisi yang lain, dalam laporan UNESCO juga mengemukakan bahwa menegakkan penggunaan bahasa ibu akan mengurangi bolos sekolah, pengulangan/tidak naik kelas dan putus sekolah yang tinggi di negaranegara berkembang, (Ghanggo Ate, Y., 2019:4). Dengan demikan, pembelajaran berbasis bahasa Ibu sangat penting untuk 
diimplementasikan dalam praktik pembelajaran di kelas-kelas awal. Bahkan, bahasa Ibu mutlak dipertahankan karena bahasa Ibu merupakan salah satu instrumen pembentuk karakter anak, (Shahih, 2017: 203).

Selain penggunaan bahasa ibu, metode pembelajaran membaca juga perlu diberikan untuk para guru SD agar anak tidak stres dan guru dapat menciptakan proses pembelajaran yang efektif. Dengan berdasarkan metode Struktur Analisis Sintesis (SAS), kata, metode suku kata, dan abjad yang disampaikan dalam bentuk permainan, pembelajaran membaca akan sangat efektif dan menyenangkan. Anak-anak sangat dekat sekali dengan dunia permainan, sejak kecil mereka suka terhadap segala permainan. Dengan bermain anak-anak belajar mengenai sesuatu yang ada di sekitarnya. Permainan dapat membuat kemampuan berpikir anak lebih dalam mencerna hal-hal yang astrak menjadi lebih konkret. Dengan bermainan, anak-anak dapat membangun rasa percaya diri anak dan kemampuan bersosialisasi dengan lingkungan sekitarnya. Pembelajaran membaca dengan mengasimilasi bahasa Indonesia dengan bahasa daerah mereka yang disajikan dengan berbagai permainan dapat menghasilkan dampak hasil belajar positif. Untuk meramu ketiganya, yaitu bahasa Indonesia, bahasa daerah, dan metode permainan seorang guru SD dituntut untuk kreatif.

Oleh karena itu diperlukan pelatihan khusus untuk merancang pembelajaran yang mengintegrasikan bahasa Indonesia dengan bahasa ibu yang disajikan dalam permainan bahasa. Pelatihan khusus tersebut dimaksudkan untuk menjawabi persoalan yang dihadapi oleh pada guru Sumba pada umumnya dan Sumba Barat Daya pada khusunya, yaitu: 1) Ada sejumlah permasalahan pendidikan yang mendesak untuk segera dituntaskan di Sumba, Nusa Tenggara Timur sebagaimana hasil temuan ACDP; 2) Permasalahan membaca pada anak sekolah dasar di daerah terpencil cukup menjadi perhatian serius; 3) Kualitas guru dan kepala sekolah yang hanya lulusan SMA ini, membuat cara mengajarkan baca dan tulis menjadi kurang efektif; 4) Kelompok Kerja Guru (KKG), yang dimaksudkan agar para guru mau aktif mencari terobosan dalam menangani masalah literasi juga tidak berjalan dan tidak mampu meningkatkan kualitas mereka; 5) Anak-anak di Sumba juga cenderung masih memakai bahasa ibu yang membuat kemampuan guru untuk mengajar, harus ditingkatkan. Lima puluh persen anakanak di Sumba masih menggunakan bahasa ibu.

Solusi yang dilaksanakan melalui pengabdian masyarakat ini adalah sebagai berikut: 1) Menjalin kerja sama antara institusi, merespon dan menindaklanjuti hasil temuan ACDP; 2) Melakukan koordinasi dengan para guru untuk melaksanakan pelatihan literasi bahasa Indonesia terintegrasi bahsa ibu; 3) Menyajikan berbagai metode dan cara bermail sambil belajar bahasa kepada para guru; 4) Menyajikan beberapa contoh pelaksanaan metode dan permainan; dan 5) Para guru mempraktikkan metode dan permainan bahasa Indonesia terintegrasi bahasa ibu.

Dengan demikian, melalui solusi di atas, maka target yang dicapai adalah: a) adanya peningkatan pemahaman para guru tentang metode dan permainan bahasa Indonesia terintegrasi bahasa ibu dan b) adanya peningkatan keterampilan menerapkan metode dan permainan bahasa Indonesia terintegrasi bahasa ibu.

\section{METODE PELAKSANAAN}

Pelatihan literasi bahasa Indonesia terintegrasi bahasa Ibu dilaksanakan: Selasa, $11 \mathrm{~s} / \mathrm{d}$ Kamis, 13 Juli 2017. Kegiatan tersebut dilaksanakan di SDK Kalembu Weri, sebagai central berbagai sekolah dasar wilayah Kecamatan Wewewa Barat, Kabupaten Sumba Barat Daya, Nusa Tenggara Timur. Metode pelatihan yang digunakan, yaitu ceramah, tanya jawab, diskusi, presentasi, simulasi, dan permainan. Materi disampaikan dengan berbagai metode dan narasumber sebagai pembicara sekaligus sebagai model dalam melakukan pembelajaran di kelas.Tahapan penyajian materi adalah: (1) 
pemaparan hasil kajian ACDP tentang kemampuan membaca siswa di Sumba, khususnya Sumba Barat Daya; (2) metode pembelajaran di kelas awal; dan (3) pembelajaran bahasa Indonesia terintegrasi bahasa Ibu di Kecamatan Wewewa Barat, Sumba, Nusa Tenggara Timur. Materi pembelajaran bahasa Indonesia terintegrasi bahasa Ibu terdiri atas beberapa sub materi, yaitu: konsep belajar dan pembelajaran, konsep literasi, konsep bahasa Ibu, media, materi, membaca dan menulis permulaan (MMP) dengan pembahasa utama terkait metode pembelajaran di kelas awal yang dikaitkan dengan bahasa Ibu, menyajikan materi dengan metode permainan, yaitu permainan ejaan, permainan suku kata, permainan kata, permainan kalimat, dan permainan sambung huruf menjadi kalimat; (4) penyusunan penerapan metode (Suku Kata dan SAS); (5) penyusunan penerapan media (kata, suku kata, dan kartu huruf); dilanjutkan (6) pelatihan penerapan strategi, metode, dan media pembelajaran bahasa Indonesia terintergasi bahasa ibu. Berikut ini adalah deskripsi tentang pelaksanaan kegiatan pengabdian kepada masyarakat.

\section{Alur Pelaksanaan Kegiatan Pengabdian Masyarakat}

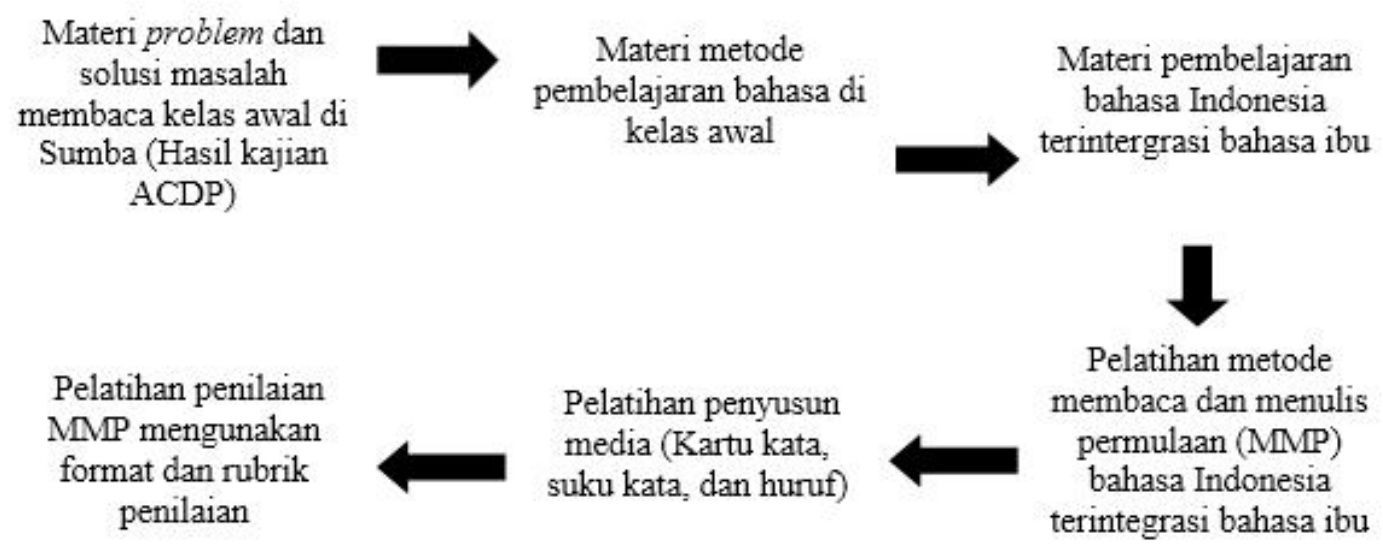

Pertama, materi problem dan solusi masalah membaca kelas awal di Sumba (Hasil kajian ACDP).

Materi tentang "problem dan solusi masalah membaca kelas awal di Sumba" (hasil kajian/temuan ACDP) dijelaskan pada awal kegiatan pengabdian. Melalui informasi awal, para guru diharapkan terinspirasi, termotivasi,

Berikut ini adalah diagram alur tentang tahapan pelaksanaan kegiatan pengabdian kepada masyarakat. dan menjiwai seluruh rangkaian kegiatan sehingga memiliki keterampilan yang diharapkan untuk melanjutkan pengalaman pelatihan tersebut di sekolah dan kelas masing-masing. Sub materi yang disajikan kepada para peserta adalah temuan tentang analisis situasi pendidikan dasar di Sumba; prioritas penanganan masalah; temuan 1: proporsi Guru yang tidak berlatar belakang pendidikan keguruan; guru lulusan SMA berdasarkan lokasi; temuan 2: rasio guru S1kekurangan di Sumba, dengan porsi terbanyak 52\% di Sumba Barat Daya; dan temuan 3: angka mengulang cenderung tinggi di kelas awal dan menurun di kelas tinggi (umumnya karena belum bisa baca, tulis, dan berhitung).

Kedua, materi metode pembelajaran bahasa di kelas awal.

Materi metode pembelajaran bahasa di kelas awal yang diberikan kepada para peserta adalah: 1) metode abjad/eja; 2) metode bunyi; 3) metode suku kata; 4) metode kupas rangkai suku kata; 5) metode kata; 6) metode global; dan 7) metode Struktural Analitik Sintesis (SAS), (Makmara, 2014: 11-14).

Ketiga, materi pembelajaran bahasa Indonesia terintegrasi bahasa Ibu di 
Kecamatan Wewewa Barat, Sumba, Nusa Tenggara Timur.

Penyajian materi ini terdiri dari berbagai sub materi yang dimaksudkan agar peserta pelatihan mendapat pemahaman yang baik dan sistematis tentang konsep yang diberikan. Sub-sub materi yang dimaksud adalah konsep-konsep tentang belajar dan pembelajaran, literasi, bahasa Ibu, media, materi, membaca dan menulis permulaan (MMP). Pada bagian MMP, prioritas pembahasan lebih diarahkan pada penggunaan metode metode pembelajaran di kelas awal yang dikaitkan dengan bahasa Ibu. Selain itu, dijelaskan, disimulasikan, dan dipraktikkan pula pengunaan metode permainan, yaitu berupa permainan ejaan, suku kata, kata, kalimat, dan sambung huruf menjadi kalimat.

Keempat, materi pelatihan metode membaca dan menulis permulaan ( $\mathrm{mmp}$ ) bahasa Indonesi terintegrasi bahasa ibu.

Materi ini diberikan kepada para peserta dengan uraian berupa pemahaman tentang MMP yang ditujukan kepada siswa kelas awal agar melek huruf, MMP dikenal siswa sebagai peralihan masa bermain ke dunia sekolah, dan MMP sebagai tahapan awal peralihan bersosialisasi di luar rumah. Materi MMP diperkenalkan, disimulasikan, dan dilatihkan kepada para peserta dengan metode permainan ejaan, suku kata, kata, kalimat, dan sambung huruf dalam bahasa Indonesia yang diintegrasikan dengan bahasa Ibu.

Kelima, materi pembuatan dan penerapan media (kartu kata, suku kata, dan huruf).

Pada penyajian materi ini, peserta dilatih secara lebih mendalam tentang pembuatan dan penerapan media (kartu huruf, suku kata, dan kata). Peserta dibentuk dalam kelompok untuk menyusun media kartu huru, suku kata, dan kata dalam bahasa Indonesia dan bahasa Ibu. Kemudian mempresentasikan kepada kelompok lain. Selain itu, simulasikan dan dilatih pula cara menerapkan media kartu huruf, suku kata, dan kata di depan peserta.
Keenam, materi pelatihan penilaian Membaca dan Menulis Permulaan (MMP).

Materi ini diberikan dan dilatihkan kepada peserta agar memiliki keterampilan yang komplit, dimulai dari pemahaman konsep, penyusunan dan penerapa metode MMP mengintegrasikan bahasa Indonesia dan bahasa Ibu, pelaksanaan pembelajaran MMP, sampai pada penilaian MMP. Penyajian materi ini dilanjutkan dengan pelatihan pengisian format dan rubrik penilaian MMP.

\section{HASIL DAN PEMBAHASAN}

Pelaksanaan pelatihan bahasa Indonesia Terintegrasi bahasa Ibu berdampak pada hasil yang sangat memuaskan. Para peserta yang terdiri dari 32 sekolah dasar seKecamatan Wewewa Barat, Kabupaten Sumba Barat Daya, Nusa Tenggara Timur mengikuti kegiatan pelatihan selama tiga hari berturut-turut dengan antusias yang tinggi. Para peserta merasa mendapat pemahaman dan keterampilan yang bertambah, khususnya dalam membantu siswa kelas awal belajar bahasa Indonesia dengan mengintegrasikannya dengan bahasa Ibu.

Para peserta mengakui bahwa pembelajaran di sekolah masing-masing diusahakan dalam bahasa Indonesia. Dengan kata lain, bahasa Ibu hanya digunakan sebagai bahasa pengantar agar anak memahami bahasa Indonesia. Melalui pelatihan ini, para guru dilatih untuk mengenalkan huruf, suku kata, kata, kalimat kepada siswa menggunakan bahasa Indonesia mengintegrasikan dengan bahasa Ibu. Dalam proses pelatihan, upaya mengintegrasikan bahasa Indonesia dan bahasa Ibu dilakukan melalui penggunaan metode Membaca dan Menulis Permulaan (MMP), yaitu: metode abjad, suku kata, kata, kalimat, dan Struktural Analitik Sistesis. Berikut ini adalah materimateri yang diberikan kepada para guru selama kegiatan pelatihan. 


\section{Jadwal dan Materi Pengabdian Masyarakat}

Materi problem dan solusi masalah

Selasa, membaca kelas awal di Sumba

11 Juli (Hasil Kajian ACDP).

2017 Materi metode pembelajaran bahasa di kelas awal.

Materi pembelajaran bahasa Indonesia terintegrasi bahasa Ibu

Rabu, di Kecamatan Wewewa Barat,

12 Juli Sumba, Nusa Tenggara Timur.

2017 Materi pelatihan metode Membaca dan Menulis Permulaan (MMP)

bahasa Indonesia terintegrasi bahasa ibu.

Materi pembuatan dan penerapan

Kamis, media (kartu kata, suku kata, dan

13 Juli huruf).

2017 Materi pelatihan penilaian

Membaca dan Menulis Permulaan

(MMP).

Pada hari pertama, Selasa, 11 Juli 2017, para guru diberikan materi yang menginspirasi agar guru mendapatkan informasi dasar pemahaman tentang pelaksanaan kegiatan pengabdian. Materi yang diberikan adalah problem dan solusi masalah membaca kelas awal di Sumba. Kemudian, para peserta diberikan materi kedua tentang metode pembelajaran bahasa di kelas awal.

Sebelum menyajikan materi kedua, para guru diberikan pre test tentang pemahaman metode yang sering digunakan dalam pembelajaran di kelas awal. Sebagian besar guru menggunakan menggunakan metode ceramah, tanya jawab, juga menggunakan metode abjad/huruf, suku kata, dan kata. Guru sangat jarang menggunakan metode kalimat dan SAS. Bahkan, sebagina besar guru belum mengenal metode SAS, apalagi menggunakannya Beberapa guru lainnya, telah mengenal metode SAS pada saat kuliah namun belum pernah menggunakannya di kelas.

Setelah melaksanakan pre test, para guru diberikan materi tentang metode pembejaran bahasa di kelas awal, yaitu: 1) metode eja/abjab/huruf, 2) metode bunyi, 3) metode suku kata, 4) metode kupas rangkai suku kata, 5) metode kata, 6) metode kalimat/global, 7) metode SAS. Dalam proses penyajian materi ini, para peserta sangat senang mendapat materi tentang metode pembelajaran di kelas awal. Peserta aktif dalam proses penyajian materi sekaligus mendalami materi dengan pertanyaanpertanyaan. Penyajian materi disertai pula dengan contoh-contoh dan aplikasinya dalam pembelajaran sehingga para guru terampil menerapkannya di sekolah masing-masing Pengabdian hari kedua, dilaksanakan pada Rabu, 12 Juli 2019. Materi yang diberikan terdiri dari dua bagian, yaitu 1) pembelajaran bahasa Indonesia terintegrasi bahasa Ibu di Kecamatan Wewewa Barat, Sumba, Nusa Tenggara Timur dan 2) pelatihan metode Membaca dan Menulis Permulaan (MMP) Bahasa Indonesi Terintegrasi Bahasa Ibu.

Penyajian materi pertama berisi tentang konsep tentang belajar dan pembelajaran. Belajar berbeda dengan pembelajaran, belajar merupakan tugas utama siswa, tanpa interaksi guru dan siswa, sedangkan pembelajaran mengharuskan adanya interaksi guru dengan siswa, siswa dengan siswa, siswa dan guru belajar bersama-sama.

Konsep berikut yang diberikan adalah pemahaman tentang literasi, yaitu kualitas/kemampuan melek huruf/aksara (kemampuan membaca dan menulis). Secara umum, literasi dimaknai sebagai kemampuan individu untuk membaca, menulis, berbicara, menghitung, dan memecahkan masalah pada tingkat keahlian yang dibutuhkan dalam keluarga dan masyarakat.

Konsep lanjutan yang dijelaskan secara singkat adalah bahasa Ibu, yaitu bahasa pertama yang diperoleh dan dikuasai oleh anak. Dalam kaitannya dengan wilayah pelatihan ini, maka bahasa pertama yang peroleh dan dikuasai oleh siswa adalah bahasa daerah Wewewa. Selanjutnya disajikan pula tentang konsep media yang dikaitkan dengan media kartu huruf, suku kata, dan kata. 
Materi berikut yang disajikan pada hari kedua berkaitan dengan metode membaca dan menulis permulaan (MMP). Materi MMP disajikan dengan penekanan pada penggunaan metode pembelajaran di kelas awal dengan mengintegrasikannya dengan bahasa Ibu. Selain itu, pada bagian akhir dari penyajian materi ini, guru dibentuk dalam kelompok-kelompok untuk berlatih dan menyiapkan simulasidan praktikpenggunaan metode permainan, yang terdiri dari permainan ejaan, suku kata, kata, kalimat, dan sambung huruf menjadi kalimat. Dalam proses berkelompok, para peserta diberikan kesempatan untuk berdiskusi menyiapkan permainan ejaan, suku kata, kata, kalimat, dan sambung huruf menjadi kalimat dalam bahasa Indonesia yang kemudian diterjemahkan dalam bahasa Wewewa, atau sebaliknya mencari kosa kata dan kalimat dalam bahasa Wewewa yang kemudian diterjemahkan dalam bahasa Indonesia. Setelah menemukan permainan-permainan dengan menggunakan berbagai metode MMP, kelompok bersimulasi dalam kelompok sebagai persiapan untuk dipraktikan agar dilihat dan dipelajari oleh kelompok lain. Setiap kelompok mendapat giliran untuk simulasi dan praktik.

Materi pelatihan pada hari ketiga, Kamis, 13 Juli 2019 adalah 1) Materi pembuatan dan penerapan media (kartu kata, suku kata, dan huruf) dan 2) Materi pelatihan penilaian Membaca dan Menulis Permulaan (MMP). Pada hari terakhir pelatihan ini, peserta berkelompok lagi untuk membuat media kartu kata dan kalimat dalam bahasa Wewewa. Setelah menyusun kata dan kalimat dalam bahasa Wewewa, kelompok melanjutkan pekerjaan tersebut dengan menyusun kata, suku kata, dan huruf dari kata semula. Dengan demikian, peserta belajar dari kalimat dan kata, kemudian merinci menjadi suku-kata dan huruf. Kelompok diberi kesempatan untuk menemukan 10 kalimat dan kosa kata dalam bahasa Wewewa yang diterjemahkan dalam bahasa Indonesia. Peserta diberi pula kesempatan untuk menggunakan klasifikasi hewan, tumbuhan, dan lain-lain yang dekat dengan lingkungan siswa. Selanjutnya diuraikan menjadi kata, suku kata dan huruf, sebagai bekal belajar agar siswa menguasai bahasa Wewewa dan bahasa Indonesia.

Para peserta semakin antusias ketika berdiskusi untuk menemukan kalimat dan kosa kata bahasa daerah sesuai tugas yang diberikan oleh pemateri. Para peserta diajak untuk memikirkan sejumlah kosa kata bahasa daerah sekaligus menerjemahkan dalam bahasa Indonesia, Misalnya, kalimat "yowa kako sakola" (dalam bahasa Wewewa) menjadi saya pergi ke sekolah (dalam bahasa Indonesia) atau kata galli (bahasa Wewewa) menjadi elang (bahasa Indonesia), kata manu (bahasa Wewewa) menjadi ayam (bahasa Indonesia), kata malawo (bahasa Wewewa) menjadi tikus (bahasa Indonesia). Para peserta menemukan kalimat dan kata dalam bahasa Wewewa dan diterjemahkan dalam bahasa Indonesia. Kemudian, peserta mempresentasikan kepada kelompok lain untuk mendapat tanggapan.

Pada bagian akhir dari sesi ini, pemateri memberikan pemahaman kepada peserta pelatihan tentang format dan rubrik penilaian MMP. Format penilaian MMP berisi aspek penilaian dan skor yang dipilih (dari 1, 2, 3, 4, dan 5 sesuai skala yang ingin digunakan oleh guru). Rubrik penilaian berisi pedoman penilaian masing-masing skala yang dipilih.

\section{KESIMPULAN}

Berdasarkan pelaksanaan kegiatan pengabdian pelatihan Bahasa Indonesia terintegrasi bahasa Ibu, diperoleh beberapa kesimpilan: 1) peserta pelatihan mendapat pemahaman tentangpentingnya pembelajaran bahasa Indonesia dengan mengintegrasikan bahasa Ibu pada pembelajaran kelas awal; 2) peserta pelatihan mendapat pemahaman yang optimal tentang metode pembelajaran bahasa pada kelas awal; 3) peserta pelatihan mendapatkan pemahaman yang baik tentang pembelajaran bahasa Indonesia terintegrasi bahasa Ibu; 4) peserta pelatihan mendapat keterampilan menerapkan metode MMP bahasa Indonesia dengan mengintegrasikan bahasa Ibu; 5) peserta pelatihan mendapat 
kesempatan untuk melatih menyusun media (kartu kata, suku kata, dan huruf) bahasa Indonesia mengintegrasikan bahasa Ibu atau bahkan mencari kosa kata bahasa Ibu yang kemudian diterjemahkan dalam bahasa Indonesia; 6) peserta pelatihan mendapat pemahaman dan keterampilan menggunakan penilaian MMP dengan menggunakan format dan rubrik penilaian.

\section{REFERENSI}

Kemendikbud. (2016). Gerakan Literasi Sekolah. Jakarta: Direktorat Jendral Pendidikan Dasar dan Menengah.

Kemitraan untuk Pengembangan Kapasitas dan Analisis Sektor Pendidikan (ACDP). (2014). Pendidikan Multi Bahasa Berbasis Bahasa Ibu (PMB$B I)$. Jakarta: Balitbang Kemendikbud.

Kemitraan untuk Pengembangan Kapasitas dan Analisis Sektor Pendidikan (ACDP). (2015). Strategi peningkatan efektivitas pendidikan dasar di sekolah/madrasah di Sumba, NTT. Jakarta: Balitbang Kemendikbud.

Makmara, Th., (2014). Pembelajaran Bahasa Tulis di Sekolah Dasar. Modul: Program Studi PGSD, Jurusan Ilmu Pendidikan, FKIP, Uversitas Nusa Cendana.

Ghanggo Ate, Y. (2019). Pengajaran Literasi Berbasis Bahasa Ibu: sebuah Alternatif Menurai Isu Literasi di Sumba. Makalah: pada orasi ilmiah dalam rangkah Wisuda Perdana Sekolah Tinggi Keguruan dan Pendidikan (STKIP) Weetebula pada tanggal 28 Januari 2019 di Weetebula, Sumba, Nusa Tenggara Timur (NTT).

Shahih, (2017). Urgensi Pemertahanan Bahasa Ibu. Jurnal: Sekolah Tinggi Agama Islam Nahdatul Ulama (STAINU) Temanggung, Vol. 22 Nomor 2, Juli-Desember. 